Pacific Journal of Mathematics

ON PERMANENTS OF CIRCULANTS 


\title{
ON PERMANENTS OF CIRCULANTS
}

\author{
HENRYK MINC
}

A recurrence formula is obtained for permanents of circulants of the form $\alpha I_{n}+\beta P+\gamma P^{2}$ and explicit formulas are deduced from it. It is shown that for doubly stochastic circulants $\alpha I_{n}+\beta P+\gamma P^{2}$ the minimum permanent lies in the interval $\left(1 / 2^{n}, 1 / 2^{n-1}\right]$.

1. Introduction. The well-known unresolved conjecture of van der Waerden asserts that in $\Omega_{n}$, the polyhedron of doubly stochastic $n \times n$ matrices, the permanent function takes its minimum value for the matrix $J_{n}$, all of whose entries are $1 / n$, i.e.,

$$
\min _{A \in \Omega_{n}} \operatorname{per}(A)=\operatorname{per}\left(J_{n}\right) \text {. }
$$

By a theorem of Birkhoff, $\Omega_{n}$ is a convex polyhedron with the permutation matrices $P_{1}, \cdots, P_{n !}$ as vertices. Thus (1) can be written in the form

$$
\min _{\theta} \operatorname{per}\left(\sum_{j=1}^{n !} \theta_{j} P_{j}\right)=\operatorname{per}\left(\sum_{j=1}^{n !} \frac{1}{n !} P_{j}\right)
$$

where the minimum is over all nonnegative $(n !)$-tuples $\theta=\left(\theta_{1}, \cdots, \theta_{n !}\right)$ satisfying $\sum_{j=1}^{n !} \theta_{j}=1$.

Since van der Waerden's conjecture is still unresolved, it is natural to ask whether

$$
\min _{\omega} \operatorname{per}\left(\sum_{j=1}^{m} \omega_{j} P_{j}\right)=\operatorname{per}\left(\sum_{j=1}^{m} \frac{1}{m} P_{j}\right),
$$

for a fixed set of permutation matrices $\left\{P_{1}, \cdots, P_{m}\right\}$, where the minimum is over all nonnegative $m$-tuples $\omega=\left(\omega_{1}, \cdots, \omega_{m}\right)$ satisfying $\sum_{j=1}^{m} \omega_{j}=1$.

In this paper we study circulants of the form $\alpha I_{n}+\beta P+\gamma P^{2}$, where $I_{n}$ is the $n \times n$ identity matrix and $P$ is the full-cycle permutation matrix with 1 's in the positions $(1,2),(2,3), \cdots,(n-1, n)$, $(n, 1)$. We obtain a recurrence formula and deduce explicit formulas for $\operatorname{per}\left(\alpha I_{n}+\beta P+\gamma P^{2}\right)$. We then specialize to doubly stochastic circulants of the form $\alpha I_{n}+\beta P+\gamma P^{2}$, obtain bounds for the minimum value of the permanent of such circulants, and show that (3) does not hold for the set $\left\{I_{n}, P, P^{2}\right\}, n \geqq 5$.

The author is indebted to Dr. David London for drawing his attention to the fact that per $\left((1 / 2) I_{n}+(1 / 2) P\right)<\operatorname{per}\left((1 / 3) I_{n}+(1 / 3) P+\right.$ $\left.(1 / 3) P^{2}\right)$, for sufficiently large $n$. 
2. Results. We begin with two formulas for the permanent of a tridiagonal matrix of the form

$$
\left[\begin{array}{ccccccccccc}
\beta & \gamma & 0 & 0 & . & . & . & 0 & 0 & 0 & 0 \\
\alpha & \beta & \gamma & 0 & . & . & . & 0 & 0 & 0 & 0 \\
0 & \alpha & \beta & \gamma & . & . & . & 0 & 0 & 0 & 0 \\
. & . & \ddots & \ddots & \ddots & & . & . & . & . \\
. & . & . & \ddots & \ddots & & . & . & . & . \\
. & . & . & . & \ddots & \ddots & . & . & . & . \\
. & . & . & . & & \ddots & \ddots & . & . & . \\
0 & 0 & 0 & 0 & . & \ddots & \ddots & \beta & \gamma & 0 & 0 \\
0 & 0 & 0 & 0 & . & . & . & \alpha & \beta & \gamma & 0 \\
0 & 0 & 0 & 0 & . & . & . & 0 & \alpha & \beta & \gamma \\
0 & 0 & 0 & 0 & . & . & . & 0 & 0 & \alpha & \beta
\end{array}\right] .
$$

Let $F_{n}(\alpha, \beta, \gamma)$ denote the matrix (4) of order $n$ and let the permanent of $F_{n}(\alpha, \beta, \gamma)$ be denoted by $f_{n}(\alpha, \beta, \gamma)$, or simply by $f_{n}$. Set $f_{0}=1$, $f_{1}=\beta$, and $f_{2}=\beta^{2}+\alpha \gamma$.

LEMMA 1 . If $n \geqq 2$, then

$$
f_{n}=\beta f_{n-1}+\alpha \gamma f_{n-2} .
$$

CoRollary. If $n \geqq 1$ and $\mu=\sqrt{\beta^{2}+4 \alpha \gamma} \neq 0$, then

$$
f_{n}=\frac{1}{\mu} r_{1}^{n+1}-\frac{1}{\mu} r_{2}^{n+1}
$$

where $r_{1}=(\beta+\mu) / 2$ and $r_{2}=(\beta-\mu) / 2$. If $\mu=0$, then

$$
f_{n}=(n+1)(\beta / 2)^{n} \text {. }
$$

(In other words, if the right side of (6) is considered as a polynomial expression in $\alpha, \beta, \gamma$, then (6) holds even in the case $\mu=0$.)

The lemma is proved easily by expanding the permanent of $F_{n}(\alpha, \beta, \gamma)$ by the first column. Formula (6) is obtained by solving the difference equation (5) subject to initial conditions.

In the next lemma, formula (5) is used to obtain a relation between the permanent of the circulant $\alpha I_{n}+\beta P+\gamma P^{2}$ and permanents of tridiagonal matrices of the form (4). 


$$
\operatorname{per}\left(\alpha I_{n}+\beta P+\gamma P^{2}\right)=f_{n}+\alpha \gamma f_{n-2}+\alpha^{n}+\gamma^{n} \text {. }
$$

Proof. A direct computation shows that the theorem holds for $n=3$. Assume that $n \geqq 4$. Denote the matrix $\alpha I_{n}+\beta P+\gamma P^{2}$ by $Q_{n}$, and the submatrix of $Q_{n}$ obtained by deleting rows $i_{1}, i_{2}$ and columns $j_{1}, j_{2}$ by $Q_{n}\left(i_{1}, i_{2} \mid j_{1}, j_{2}\right)$. Expand the permanent of $Q_{n}$ by the first two columns:

$$
\begin{aligned}
\operatorname{per}\left(Q_{n}\right)= & \alpha^{2} \operatorname{per}\left(Q_{n}(1,2 \mid 1,2)\right)+\beta \gamma \operatorname{per}\left(Q_{n}(1, n-1 \mid 1,2)\right) \\
& +\left(\alpha \gamma+\beta^{2}\right) \operatorname{per}\left(Q_{n}(1, n \mid 1,2)\right)+\alpha \gamma \operatorname{per}\left(Q_{n}(2, n-1 \mid 1,2)\right) \\
& +\alpha \beta \operatorname{per}\left(Q_{n}(2, n \mid 1,2)\right)+\gamma^{2} \operatorname{per}\left(Q_{n}(n-1, n \mid 1,2)\right) \\
= & \alpha^{n}+\alpha \beta \gamma f_{n-3}+\left(\alpha \gamma+\beta^{2}\right) f_{n-2}+\alpha^{2} \gamma^{2} f_{n-4}+\alpha \beta \gamma f_{n-3}+\gamma^{n} \\
= & \beta f_{n-1}+\alpha \gamma f_{n-2}+\alpha \gamma\left(\beta f_{n-3}+\alpha \gamma f_{n-4}\right)+\alpha^{n}+\gamma^{n} \\
= & f_{n}+\alpha \gamma f_{n-2}+\alpha^{n}+\gamma^{n} .
\end{aligned}
$$

We now use the preceding result to obtain a recurrence formula for the permanent of $\alpha I_{n}+\beta P+\gamma P^{2}$, and then to deduce explicit formulas for these circulants.

Theorem 1. If $Q_{n}=\alpha I_{n}+\beta P+\gamma P^{2}$ and $n \geqq 5$, then

$$
\begin{aligned}
\operatorname{per}\left(Q_{n}\right)= & \beta \operatorname{per}\left(Q_{n-1}\right)+\alpha \gamma \operatorname{per}\left(Q_{n-2}\right) \\
& +\alpha^{n-1}(\alpha-\beta-\gamma)+\gamma^{n-1}(\gamma-\alpha-\beta) .
\end{aligned}
$$

Proof. We use (7) and (5) to transform the right-hand side of (8) as follows:

$$
\begin{aligned}
\beta \text { per } & \left(Q_{n-1}\right)+\alpha \gamma \operatorname{per}\left(Q_{n-2}\right)+\alpha^{n-1}(\alpha-\beta-\gamma)+\gamma^{n-1}(\gamma-\alpha-\beta) \\
= & \beta f_{n-1}+\beta \alpha \gamma f_{n-3}+\beta \alpha^{n-1}+\beta \gamma^{n-1}+\alpha \gamma f_{n-2}+\alpha^{2} \gamma^{2} f_{n-4}+\alpha^{n-1} \gamma \\
& +\alpha \gamma^{n-1}+\alpha^{n}-\alpha^{n-1} \beta-\alpha^{n-1} \gamma+\gamma^{n}-\alpha \gamma^{n-1}-\beta \gamma^{n-1} \\
= & \left(\beta f_{n-1}+\alpha \gamma f_{n-2}\right)+\alpha \gamma\left(\beta f_{n-3}+\alpha \gamma f_{n-4}\right)+\alpha^{n}+\gamma^{n} \\
= & f_{n}+\alpha \gamma f_{n-2}+\alpha^{n}+\gamma^{n} \\
= & \operatorname{per}\left(Q_{n}\right) .
\end{aligned}
$$

The difference equation (8) can now be solved subject to the conditions

$$
\begin{aligned}
& \operatorname{per}\left(Q_{3}\right)=\alpha^{3}+\beta^{3}+\gamma^{3}+3 \alpha \beta \gamma \\
& \operatorname{per}\left(Q_{4}\right)=\alpha^{4}+\beta^{4}+\gamma^{4}+4 \alpha \beta^{2} \gamma+2 \alpha^{2} \gamma^{2} \\
& \operatorname{per}\left(Q_{5}\right)=\alpha^{5}+\beta^{5}+\gamma^{5}+5 \alpha \beta^{3} \gamma+5 \alpha^{2} \beta \gamma^{2}, \quad \text { etc., }
\end{aligned}
$$

which are computed directly using a Laplace expansion. We obtain the following explicit formula. 
THEOREM 2. If $n \geqq 3$, then

$$
\operatorname{per}\left(\alpha I_{n}+\beta P+\gamma P^{2}\right)=r_{1}^{n}+r_{2}^{n}+\alpha^{n}+\gamma^{n}
$$

where $r_{1}$ and $r_{2}$ are the roots of $x^{2}-\beta x-\alpha \gamma=0$.

Alternatively, formula (9) can be obtained from (7) and (6) if $\mu \neq 0$, or from (7) and $\left(6^{\prime}\right)$ in case $\mu=0$. Thus if $\mu \neq 0$ :

$$
\begin{aligned}
\operatorname{per}\left(\alpha I_{n}+\beta P+\gamma P^{2}\right)= & f_{n}+\alpha \gamma f_{n-2}+\alpha^{n}+\gamma^{n} \\
= & \frac{1}{\mu} r_{1}^{n+1}-\frac{1}{\mu} r_{2}^{n+1}+\frac{\alpha \gamma}{\mu} r_{1}^{n-1}-\frac{\alpha \gamma}{\mu} r_{2}^{n-1} \\
& +\alpha^{n}+\gamma^{n} \\
= & \frac{1}{\mu}\left(r_{1}^{n+1}-r_{2}^{n+1}-r_{1} r_{2}\left(r_{1}^{n-1}-r_{2}^{n-1}\right)\right)+\alpha^{n}+\gamma^{n} \\
= & \frac{1}{\mu}\left(r_{1}^{n}+r_{2}^{n}\right)\left(r_{1}-r_{2}\right)+\alpha^{n}+\gamma^{n} \\
= & r_{1}^{n}+r_{2}^{n}+\alpha^{n}+\gamma^{n},
\end{aligned}
$$

since $\alpha \gamma=-r_{1} r_{2}$ and $\mu=r_{1}-r_{2}$. The case $\mu=0$ is proved similarly.

Formulas (8) and (9) have been obtained in [2] for the special case $\alpha=\beta=\gamma$.

THEOREM 3. If $n \geqq 3$, then

$$
\operatorname{per}\left(\alpha I_{n}+\beta P+\gamma P^{2}\right)=\alpha^{n}+\beta^{n}+\gamma^{n}+\sum_{t=1}^{[n / 2]} c_{t}^{(n)} \alpha^{t} \beta^{n-2 t} \gamma^{t}
$$

where $c_{t}^{(n)}=2^{-(n-2 t-1)} \sum_{k=t}^{[n / 2]}\left(\begin{array}{c}n \\ 2 k\end{array}\right)\left(\begin{array}{l}k \\ t\end{array}\right)$.

Proof. Let $r_{1}=(\beta+\mu) / 2$ and $r_{2}=(\beta-\mu) / 2$, where $\mu=\sqrt{\beta^{2}+4 \alpha \gamma}$. Then by formula (9),

$$
\begin{aligned}
\operatorname{per} & \left(\alpha I_{n}+\beta P+\gamma P^{2}\right) \\
& =\alpha^{n}+\gamma^{n}+\left(\frac{\beta+\mu}{2}\right)^{n}+\left(\frac{\beta-\mu}{2}\right)^{n} \\
& =\alpha^{n}+\gamma^{n}+2^{-(n-1)} \sum_{k=0}^{[n / 2]}\left(\begin{array}{c}
n \\
2 k
\end{array}\right) \beta^{n-2 k e}\left(\beta^{2}+4 \alpha \gamma\right)^{k} \\
& =\alpha^{n}+\gamma^{n}+2^{-(n-1)} \sum_{k=0}^{[n / 2]}\left(\begin{array}{c}
n \\
2 k
\end{array}\right) \sum_{t=0}^{k}\left(\begin{array}{c}
k \\
t
\end{array}\right) \beta^{n-2 t}(4 \alpha \gamma)^{t} \\
& =\alpha^{n}+\beta^{n}+\gamma^{n}+\sum_{t=1}^{[n / 2]}\left(\sum_{k=t}^{[n ; 2]} 2^{-(n-2 t-1)}\left(\begin{array}{c}
n \\
2 k
\end{array}\right)\left(\begin{array}{c}
k \\
t
\end{array}\right)\right) \alpha^{t} \beta^{n-2 t} \gamma^{t} .
\end{aligned}
$$

The following alternative form of formula (10) can be proved by induction: 
(11)

$$
\left\{\begin{array}{l}
\operatorname{per}\left(\alpha I_{n}+\beta P+\gamma P^{2}\right)=\alpha^{n}+\beta^{n}+\gamma^{n}+\sum_{t=1}^{[n / 2]} c_{t}^{(n)} \alpha^{t} \beta^{n-2 t} \gamma^{t}, \\
\text { where } c_{1}^{(n)}=n, c_{n / 2}^{(n)}=2 \text { in case } n \text { is even, } \\
\text { and } c_{t}^{(n)}=c_{t}^{(n-1)}+c_{t-1}^{(n-2)}, 1<t<n / 2 .
\end{array}\right.
$$

The cases $n=3$ and 4 can be easily verified. If $Q_{n}=\alpha I_{n}+\beta P+$ $\gamma P^{2}, n \geqq 5$, then by (8),

$$
\begin{aligned}
\operatorname{per}\left(Q_{n}\right)= & \beta \operatorname{per}\left(Q_{n-1}\right)+\alpha \gamma \operatorname{per}\left(Q_{n-2}\right)+\alpha^{n-1}(\alpha-\beta-\gamma) \\
& +\gamma^{n-1}(\gamma-\alpha-\beta) \\
= & \alpha^{n-1} \beta+\beta^{n}+\beta \gamma^{n-1}+\sum_{t=1}^{[(n-1) / 2]} c_{t}^{(n-1)} \alpha^{t} \beta^{n-2 t} \gamma^{t} \\
& +\alpha^{n-1} \gamma+\alpha \beta^{n-2} \gamma+\alpha \gamma^{n-1}+\sum_{s=1}^{[n / 2]-1} c_{s}^{(n-2)} \alpha^{s+1} \beta^{n-2 s+2} \gamma^{s+1} \\
& +\alpha^{n-1}(\alpha-\beta-\gamma)+\gamma^{n-1}(\gamma-\alpha-\beta) \\
= & \alpha^{n}+\beta^{n}+\gamma^{n}+\alpha \beta^{n-2} \gamma+c_{1}^{(n-1)} \alpha \beta^{n-2} \gamma+\sum_{t=2}^{[(n-1) / 2]} c_{t}^{(n-1)} \alpha^{t} \beta^{n-2 t} \gamma^{t} \\
& +\sum_{t=2}^{[n / 2]} c_{t-1}^{(n-2)} \alpha^{t} \beta^{n-2 t} \gamma^{t} \\
= & \left\{\begin{array}{c}
\alpha^{n}+\beta^{n}+\gamma^{n}+\left(1+c_{1}^{(n-1)}\right) \alpha \beta^{n-2} \gamma+\sum_{t=2}^{[n / 2]}\left(c_{t}^{(n-1)}+c_{t-1}^{(n-2)}\right) \alpha^{t} \beta^{n-2 t} \gamma^{t} \\
\alpha^{n}+\beta^{n}+\gamma^{n}+\left(1+c_{1}^{(n-1)}\right) \alpha \beta^{n-2} \gamma+\sum_{t=2}^{[n / 2]-1}\left(c_{t}^{(n-1)}+c_{t-1}^{(n-2)}\right) \alpha^{t} \beta^{n-2 t} \gamma^{t} \\
\quad 2 \alpha^{n / 2} \gamma^{n / 2},
\end{array}\right.
\end{aligned}
$$

and formula (11) follows easily.

Formula (11) allows us to construct a table of coefficients $c_{t}^{(n)}$ in the manner of Pascal's triangle.

\begin{tabular}{r|r|r|r|r|r|r}
$n$ & $c_{1}^{(n)}$ & $c_{2}^{(n)}$ & \multicolumn{1}{|c|}{$c_{3}^{(n)}$} & $c_{4}^{(n)}$ & $c_{5}^{(n)}$ & $c_{6}^{(n)}$ \\
\hline 3 & 3 & & & & & \\
4 & 4 & 2 & & & & \\
5 & 5 & 5 & & & & \\
6 & 6 & 9 & 2 & & & \\
7 & 7 & 14 & 7 & & & \\
8 & 8 & 20 & 16 & 2 & & \\
9 & 9 & 27 & 30 & 9 & & \\
10 & 10 & 35 & 50 & 25 & 2 & \\
11 & 11 & 44 & 77 & 55 & 11 & \\
12 & 12 & 54 & 112 & 105 & 36 & 2
\end{tabular}


In the remainder of this paper we assume that $\alpha I_{n}+\beta P+\gamma P^{2}$ is doubly stochastic, i.e., that $\alpha, \beta, \gamma$ are nonnegative and $\alpha+\beta+\gamma=1$.

THEOREM 4. If $\alpha, \beta, \gamma$ are nonnegative then

$$
\frac{1}{2^{n}}<\min _{\alpha+\beta+\gamma=1}\left(\operatorname{per}\left(\alpha I_{n}+\beta P+\gamma P^{2}\right)\right) \leqq \frac{1}{2^{n-1}} .
$$

Proof. The right inequality in (12) follows immediately from the fact that

$$
\operatorname{per}\left(\frac{1}{2} I_{n}+\frac{1}{2} P\right)=\frac{1}{2^{n-1}} .
$$

We prove the left inequality by showing that

$$
\operatorname{per}\left(\alpha I_{n}+\beta P+\gamma P^{2}\right)>\frac{1}{2^{n}}
$$

for any nonnegative $\alpha, \beta, \gamma$ satisfying $\alpha+\beta+\gamma=1$. If any of $\alpha$, $\beta$, $\gamma$ exceeds $1 / 2$ then (13) clearly holds, since by (10)

$$
\operatorname{per}\left(\alpha I_{n}+\beta P+\gamma P^{2}\right) \geqq \alpha^{n}+\beta^{n}+\gamma^{n} \text {. }
$$

Suppose that

$$
0 \leqq \alpha \leqq \frac{1}{2}, 0 \leqq \beta \leqq \frac{1}{2}, 0 \leqq \gamma \leqq \frac{1}{2}, \alpha+\beta+\gamma=1 .
$$

We assume, without loss of generality, that $\alpha \geqq \gamma$, and assert that under these conditions

$$
r_{1} \geqq \frac{1}{2} \text { and }\left|r_{2}\right| \leqq \alpha
$$

where $r_{1}=(1 / 2)\left(\beta+\sqrt{\beta^{2}+4 \alpha \gamma}\right)$ and $r_{2}=(1 / 2)\left(\beta-\sqrt{\beta^{2}+4 \alpha \gamma}\right)$. We use the method of Lagrange's multipliers to determine the stationary points of the function $r_{1}=r_{1}(\alpha, \beta, \gamma)$. Let

$$
F(\alpha, \beta, \gamma)=\frac{1}{2}\left(\beta+\sqrt{\beta^{2}+4 \alpha \gamma}\right)+\lambda(\alpha+\beta+\gamma-1) .
$$

The necessary conditions for a stationary point are

$$
\begin{aligned}
& \frac{\partial F}{\partial \alpha}=\frac{\gamma}{\mu}+\lambda=0, \\
& \frac{\partial F}{\partial \beta}=\frac{1}{2}\left(1+\frac{\beta}{\mu}\right)+\lambda=\frac{r_{1}}{\mu}+\lambda=0,
\end{aligned}
$$




$$
\frac{\partial F}{\partial \gamma}=\frac{\alpha}{\mu}+\lambda=0 .
$$

Where $\mu=\sqrt{\beta^{2}+4 \alpha \gamma}$, i.e., we must have $\alpha=\gamma=r_{1}$. But then

$$
2 \alpha=\beta+\sqrt{\beta^{2}+4 \alpha^{2}},
$$

i.e.,

$$
4 \alpha^{2}-4 \alpha \beta+\beta^{2}=\beta^{2}+4 \alpha^{2},
$$

which implies that either $\beta=0$ and $\alpha=\gamma=1 / 2$, or $\alpha=\gamma=0$ and $\beta=1$. In any case the function $r_{1}(\alpha, \beta, \gamma)$ has no minimum in the interior of region (14). It is easy to verify that its minimum value on the boundary is $1 / 2$.

We proceed to the second inequality in (15). Suppose that $\left|r_{2}\right|>$ $\alpha$, i.e., that

$$
\sqrt{\beta^{2}+4 \alpha \gamma}-\beta>2 \alpha
$$

or

$$
\beta^{2}+4 \alpha \gamma>\beta^{2}+4 \alpha \beta+4 \alpha^{2} \text {. }
$$

Now $\alpha$ cannot be 0 , since $\alpha \geqq \gamma$ and $\beta \leqq 1 / 2$. Hence (16) implies that

$$
\gamma>\alpha+\beta,
$$

i.e.,

$$
\gamma>\frac{1}{2}
$$

which contradicts (14). Therefore the inequalities (15) hold. Thus for any $\alpha, \beta, \gamma$ satisfying (14) we have

$$
\begin{aligned}
\operatorname{per}\left(\alpha I_{n}+\beta P+\gamma P^{2}\right) & =r_{1}^{n}+r_{2}^{n}+\alpha^{n}+\gamma^{n} \\
& \geqq r_{1}^{n}+\gamma^{n}+\left(\alpha^{n}-\left|r_{2}\right|^{n}\right) \\
& >r_{1}^{n} \\
& \geqq \frac{1}{2^{n}} .
\end{aligned}
$$

THEOREM 5. If $\alpha, \beta, \gamma$ are nonnegative numbers, $n \geqq 5$, then

$$
\min _{\alpha+\beta+\gamma=1}\left(\operatorname{per}\left(\alpha I_{n}+\beta P+\gamma P^{2}\right)\right)<\operatorname{per}\left(\frac{1}{3} I_{n}+\frac{1}{3} P+\frac{1}{3} P^{2}\right) .
$$

In other words, the minimum of the permanent function on the convex hull of $I_{n}, P, P^{2}, n \geqq 5$, is not attained for $\alpha=\beta=\gamma=1 / 3$. 
Proof. By Theorem 4,

$$
\min _{\alpha+\beta+\gamma=1}\left(\operatorname{per}\left(\alpha I_{n}+\beta P+\gamma P^{2}\right) \leqq \frac{1}{2^{n-1}} .\right.
$$

From (9) we compute

$$
\begin{aligned}
\operatorname{per}\left(\frac{1}{3} I_{n}+\frac{1}{3} P+\frac{1}{3} P^{2}\right) & =\left(\frac{1+\sqrt{5}}{6}\right)^{n}+\left(\frac{1-\sqrt{5}}{6}\right)^{n}+\frac{1}{3^{n}}+\frac{1}{3^{n}} \\
& >\left(\frac{1+\sqrt{5}}{6}\right)^{n}+\frac{1}{3^{n}},
\end{aligned}
$$

which is greater than $1 / 2^{n-1}$ for $n \geqq 10$. It can be checked by computation, that (17) holds for $5 \leqq n \leqq 9$ as well.

An explicit formula for $\min _{\alpha+\beta+\gamma=1}\left(\operatorname{per}\left(\alpha I_{n}+\beta P+\gamma P^{2}\right)\right), \alpha, \beta, \gamma \geqq$ 0 , appears to be out of reach. The available numerical data for $n \leqq 18$ seem to indicate that the values of $\alpha, \beta, \gamma$, at which the minimum is attained are the same for $n=2 k-1$ and $n=2 k$, for any $k$, but that otherwise they vary with $n$.

\section{REFERENCES}

1. Bruce W. King and Francis D. Parker, A Fibonacci matrix and the permanent function, Fibonacci Quart., 7 (1969), 539-544.

2. Henryk Minc, Permanents of (0,1)-Circulants, Canad. Math. Bull., 7 (1964), 253-263.

3. N. Metropolis, M. L. Stein and P. R. Stein, Permanents of cyclic $(0,1)$ matrices, J. Combinatorial Theory, 7 (1969), 291-321.

Received February 11, 1971 and in revised form June 16, 1971. This research was supported by the U.S. Air Force Office of Scientific Research under Grant AFOSR 69867.

University of California, Santa Barbara

AND

Technion, Israel Institute of Technology, Haifa 


\section{PACIFIC JOURNAL OF MATHEMATICS}

\section{EDITORS}

\author{
H. SAMELSON \\ Stanford University \\ Stanford, California 94305 \\ C. R. HOBBY \\ University of Washington \\ Seattle, Washington 98105
}

\section{J. DuGundJI}

Department of Mathematics University of Southern California Los Angeles, California 90007

RICHARD ARENS

University of California

Los Angeles, California 90024

\section{ASSOCIATE EDITORS}
E. F. BECKENBACH
B. H. NeumanN
F. WOLF
K. YOSHIDA

\section{SUPPORTING INSTITUTIONS}

\author{
UNIVERSITY OF BRITISH COLUMBIA \\ CALIFORNIA INSTITUTE OF TECHNOLOGY \\ UNIVERSITY OF CALIFORNIA \\ MONTANA STATE UNIVERSITY \\ UNIVERSITY OF NEVADA \\ NEW MEXICO STATE UNIVERSITY \\ OREGON STATE UNIVERSITY \\ UNIVERSITY OF OREGON \\ OSAKA UNIVERSITY
}

\author{
UNIVERSITY OF SOUTHERN CALIFORNIA \\ STANFORD UNIVERSITY \\ UNIVERSITY OF TOKYO \\ UNIVERSITY OF UTAH \\ WASHINGTON STATE UNIVERSITY \\ UNIVERSITY OF WASHINGTON \\ AMERICAN MATHEMATICAL SOCIETY \\ NAVAL WEAPONS CENTER
}

The Supporting Institutions listed above contribute to the cost of publication of this Journal, but they are not owners or publishers and have no responsibility for its content or policies.

Mathematical papers intended for publication in the Pacific Journal of Mathematics should be in typed form or offset-reproduced, (not dittoed), double spaced with large margins. Underline Greek letters in red, German in green, and script in blue. The first paragraph or two must be capable of being used separately as a synopsis of the entire paper. The editorial "we" must not be used in the synopsis, and items of the bibliography should not be cited there unless absolutely necessary, in which case they must be identified by author and Journal, rather than by item number. Manuscripts, in duplicate if possible, may be sent to any one of the four editors. Please classify according to the scheme of Math. Rev. Index to Vol. 39. All other communications to the editors should be addressed to the managing editor, Richard Arens, University of California, Los Angeles, California, 90024.

50 reprints are provided free for each article; additional copies may be obtained at cost in multiples of 50 .

The Pacific Journal of Mathematics is published monthly. Effective with Volume 16 the price per volume (3 numbers) is $\$ 8.00$; single issues, $\$ 3.00$. Special price for current issues to individual faculty members of supporting institutions and to individual members of the American Mathematical Society: $\$ 4.00$ per volume; single issues $\$ 1.50$. Back numbers are available.

Subscriptions, orders for back numbers, and changes of address should be sent to Pacific Journal of Mathematics, 103 Highland Boulevard, Berkeley, California, 94708.

PUBLISHED BY PACIFIC JOURNAL OF MATHEMATICS, A NON-PROFIT CORPORATION

Printed at Kokusai Bunken Insatsusha (International Academic Printing Co., Ltd.), 270, 3-chome Totsuka-cho, Shinjuku-ku, Tokyo 160, Japan. 


\section{Pacific Journal of Mathematics}

\section{Vol. 42, No. $2 \quad$ February, 1972}

Stephen Richard Bernfeld, The extendability of solutions of perturbed scalar differential equations ................................. 277

James Edwin Brink, Inequalities involving $f_{-} p$ and $f^{(n)}{ }_{q}$ for $f$ with $n$

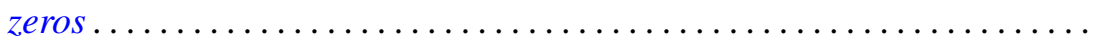

Orrin Frink and Robert S. Smith, On the distributivity of the lattice of filters of a groupoid

Donald Goldsmith, On the density of certain cohesive basic sequences .... 323

Charles Lemuel Hagopian, Planar images of decomposable continua . . . . . 329

W. N. Hudson, A decomposition theorem for biadditive processes ........ 333

W. N. Hudson, Continuity of sample functions of biadditive processes......

Masako Izumi and Shin-ichi Izumi, Integrability of trigonometric series.

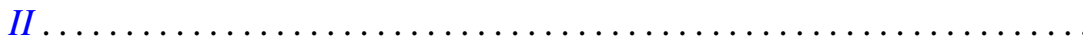

H. M. Ko, Fixed point theorems for point-to-set mappings and the set of

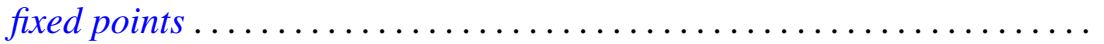

Gregers Louis Krabbe, An algebra of generalized functions on an open interval: two-sided operational calculus ...

Thomas Latimer Kriete, III, Complete non-selfadjointness of almost selfadjoint operators.................................

Shiva Narain Lal and Siya Ram, On the absolute Hausdorff summability of a Fourier series .

Ronald Leslie Lipsman, Representation theory of almost connected groups...

James R. McLaughlin, Integrated orthonormal series.... . .

H. Minc, On permanents of circulants.

Akihiro Okuyama, On a generalization of $\Sigma$-spaces.....

Norberto Salinas, Invariant subspaces and operators of class $(S)$

James D. Stafney, The spectrum of certain lower triangular matrices as operators on the $l_{p}$ spaces .......................

Arne Stray, Interpolation by analytic functions

$\mathrm{Li} \mathrm{Pi} \mathrm{Su}$, Rings of analytic functions on any subset of the complex plane.

R. J. Tondra, A property of manifolds compactly equivalent to compact manifolds.... 